\title{
First-pass myocardial stress perfusion MRI using k-t BLAST at an open MR-system: initial results in comparison to FFR measurements
}

Ortrud Kosiek ${ }^{1 *}$, Katharina A Strach, Bernhard Schnackenburg ${ }^{3}$, Alexander Schmeisser ${ }^{2}$, Jan Smid², Friederike Walz ${ }^{2}$, Jens Ricke ${ }^{1}$, Frank Fischbach ${ }^{1}$

From 16th Annual SCMR Scientific Sessions

San Francisco, CA, USA. 31 January - 3 February 2013

\section{Background}

First-pass myocardial stress perfusion MR imaging (MRI) is routinely used for the detection of myocardial ischemia in patients with suspected or known coronary artery disease (CAD). Up to now, cardiac MRI stress testing had to be performed in a closed bore environment. To allow for MR stress perfusion in claustrophobic patients and to improve monitoring during stress examination and in critically ill patients an open MR platform seems desirable. Recently, an open 1.0T MRsystem with high gradient performance has been introduced, which may allow for first-pass myocardial stress perfusion in combination with fast data acquisition techniques such as k-t BLAST.

Therefore, the aim of our study was to evaluate 1) feasibility of adenosine stress perfusion (ASP) MRI using k-t
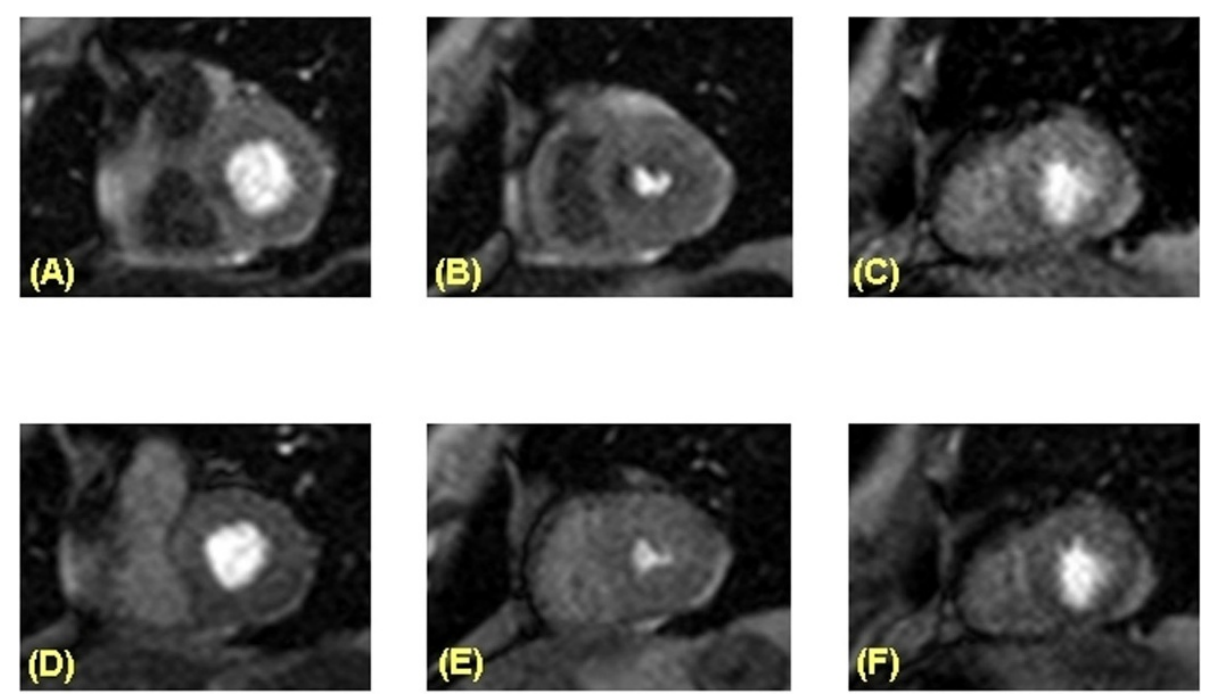

Figure 1 Adenosine stress perfusion (stress study A-C, rest study D-F) MRI in a 81 year old patient with increasing dyspnoea. Stress-induced perfusion deficits septal in the basal (A) and mid-ventricular (B) segments without correlate during resting conditions (D-F). Conventional angiography revealed a hemodynamically relevant (fractional flow reserve <0.8) stenosis in a septal coronary artery branch.

'Department of Radiology and Nuclear Medicine, University Magdeburg,

Magdeburg, Germany

Full list of author information is available at the end of the article

(c) 2013 Strach et al; licensee BioMed Central Ltd. This is an Open Access article distributed under the terms of the Creative Commons 
BLAST in patients with suspected or known CAD in a clinical setting as well as 2) Contrast Enhancement Ratio (CER) and image quality at an open MR system.

\section{Methods}

58 patients (18 female, 40 male; $62+/-13$ years) with known or suspected CAD underwent a standard ASP at an open Panorama HFO 1.0 Tesla System (Philips Healthcare, Best, Netherlands). First-pass perfusion was acquired using a k-space segmented T1-weighted gradient-echo sequence (in-plane resolution $3 \times 3 \mathrm{~mm} 2$, slice thickness 10 $\mathrm{mm}, \mathrm{k}-\mathrm{t}$ factor 3.5 ) at rest and during i.v. adenosine administration $(140 \mu \mathrm{g} / \mathrm{kg}$ BW for 4 minutes). The CER (=myocardial peak signal - myocardial baseline signal/ myocardial baseline signal) for stress perfusion studies and overall image quality (4-point grading scale: 4 : excellent; 1 : non-diagnostic) both of rest and stress examinations were assessed. A semiquantitative analysis of dark rim artifacts was performed and transmural extent $(1:<25 \% ; 2: 25-49 \%$; 3:50-74\%; 4: 75-100\%) evaluated. Hemodynamically significant $\mathrm{CAD}$ was defined as fractional flow reserve $<0.8$ using conventional coronary angiography.

\section{Results}

All examinations $(\mathrm{n}=58 / 58)$ were completed successfully. CER of stress perfusion was $2.52+/-1.14$. Overall image quality was $3.37+/-0.67$ for rest and $3.54+/-0.66$ for stress perfusion. Dark rim artefacts appeared in 129 of 928 slices $(14 \%)$ and were predominately subendocardial (1:93/129, 72\%; 2:15/129, 12\%; 3:12/129, 9\%; 4:9/129, $7 \%)$. Sensitivity and specificity for detection of significant $\mathrm{CAD}$ was $91 \%$ and $82 \%$, respectively.

\section{Conclusions}

First-pass stress perfusion MR imaging at an open $1.0 \mathrm{~T}$ MR-system is feasible in a clinical setting and yields promising results for the detection of significant coronary artery stenosis. Additionally, using k-t BLAST ASP provides good image quality and contrast, while preserving good temporal and spatial resolution.

\section{Funding}

None.

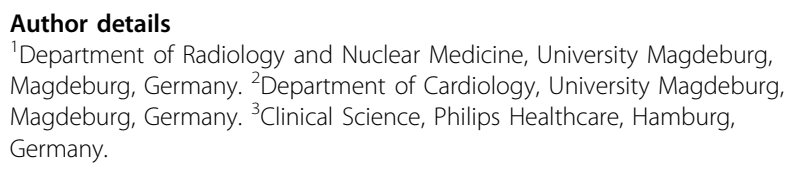

Published: 30 January 2013
doi:10.1186/1532-429X-15-S1-P184

Cite this article as: Kosiek et al.: First-pass myocardial stress perfusion MRI using k-t BLAST at an open MR-system: initial results in comparison to FFR measurements. Journal of Cardiovascular Magnetic Resonance 2013 15(Suppl 1):P184.
Submit your next manuscript to BioMed Central and take full advantage of:

- Convenient online submission

- Thorough peer review

- No space constraints or color figure charges

- Immediate publication on acceptance

- Inclusion in PubMed, CAS, Scopus and Google Scholar

- Research which is freely available for redistribution

Submit your manuscript at www.biomedcentral.com/submit 